OPEN ACCESS

Edited by:

Rudolf Lucas,

Augusta University, United States

Reviewed by:

Rahul Kashyap, Mayo Clinic, United States

Cassiano Felippe

Gonçalves-de-Albuquerque, Rio de Janeiro State Federal

University, Brazil

*Correspondence:

Francisco Garcia Soriano gsoriano@usp.br

${ }^{\text {t}}$ These authors have contributed equally to this work

Specialty section: This article was submitted to Inflammation,

a section of the journal

Frontiers in Immunology

Received: 12 September 2020 Accepted: 29 December 2020 Published: 15 February 2021

Citation:

Gritte RB, Souza-Siqueira T, Curi R, Machado MCC and Soriano FG (2021) Why Septic Patients Remain Sick After Hospital Discharge?

Front. Immunol. 11:605666. doi: 10.3389/fimmu.2020.605666

\section{Why Septic Patients Remain Sick After Hospital Discharge?}

\author{
Raquel Bragante Gritte ${ }^{1 \dagger}$, Talita Souza-Siqueira ${ }^{1 \dagger}$, Rui Curi ${ }^{1,2}$, \\ Marcel Cerqueira Cesar Machado ${ }^{3}$ and Francisco Garcia Soriano ${ }^{4,5 *}$ \\ ${ }^{1}$ Interdisciplinary Post-Graduate Program in Health Sciences, Cruzeiro do Sul University, Sao Paulo, Brazil, \\ 2 Immunobiological Production Section, Bioindustrial Center, Butantan Institute, São Paulo, Brazil, ${ }^{3}$ Department of \\ Emergency Medicine, University of São Paulo, São Paulo, Brazil, ${ }^{4}$ University Hospital, University of São Paulo, São Paulo, \\ Brazil, 5 Internal Medicine Department, School of Medicine, University of São Paulo, São Paulo, Brazil
}

Sepsis is well known to cause a high patient death rate (up to 50\%) during the intensive care unit (ICU) stay. In addition, sepsis survival patients also exhibit a very high death rate after hospital discharge compared to patients with any other disease. The addressed question is then: why septic patients remain ill after hospital discharge? The cellular and molecular mechanisms involved in the high rate of septic patient deaths are still unknown. We described herein the studies that investigated the percentage of septic patients that died after hospital discharge ranging from 90 days up to 5 years. We also reported the symptoms of septic patients after hospital discharge and the development of the recently called post-sepsis syndrome (PSS). The most common symptoms of the PSS are cognitive disabilities, physical functioning decline, difficulties in performing routine daily activities, and poor life quality. The PSS also associates with quite often reinfection and rehospitalization. This condition is the cause of the high rate of death mentioned above. We reported the proportion of patients dying after hospital discharge up to 5 years of followed up and the PSS symptoms associated. The authors also discuss the possible cellular and metabolic reprogramming mechanisms related with the low survival of septic patients and the occurrence of PSS.

Keywords: inflammation, septicemia, post sepsis syndrome, metabolic reprogramming, leukocytes

\section{INTRODUCTION: SEPSIS DEFINITION AND COSTS}

Sepsis is a systemic organ dysfunction associated with unregulated host response to infection $(1,2)$. Septic shock is a subset of sepsis in which underlying circulatory and cellular/metabolic abnormalities are profound enough to substantially increase mortality. Patients with septic shock can be identified with persisting hypotension requiring vasopressors to maintain MAP $\geq 65 \mathrm{~mm} \mathrm{Hg}$ and having a serum lactate level $>2 \mathrm{mmol} / \mathrm{L}(18 \mathrm{mg} / \mathrm{dl})$ despite adequate volume resuscitation.

The unregulated inflammatory response and consequent loss of generalized organ function in septic shock can lead the patient to death. Hospital mortality of patients with septic shock is more than $40 \%$ (2). Sepsis is widely recognized as a highly life-threatening condition associated with a high rate of patient deaths during intensive care unit (ICU) stay in the whole world (3).

Several pathogens can cause sepsis; bacterial or fungal infections represent the majority of cases. Despite this fact, negative blood culture for microorganisms has a prevalence of up to $42 \%$ of septic 
patients (4). There are few reports on viral infections causing sepsis. The incidence of viral sepsis is not precisely known, and there is insufficient information to make an accurate estimate; diagnosing viral sepsis is very rare. It has been reported that almost all viruses can cause sepsis when the patient has an impaired immune function (4). The SPREAD study (Sepsis Prevalence Assessment Database) reported about two hundred ninety cases of sepsis per 100 thousand populations in Brazil, with a mortality of up to $55 \%$. Septic patients occupy about onethird of intensive care units $(5,6)$.

In 2017, global estimates sepsis incidence and mortality indicated 48,9 million new cases worldwide. The number of deaths reached up to 11 million, representing $19.7 \%$ of the patients (7). The expenses ranged from US $\$ 24,638$ to US $\$ 38,298$ per patient in the USA (8), from 23,000 to $29,000 €$ in Europe (9), and around US\$ 9,600 in Brazil (10).

There is substantial knowledge of long-term sepsis symptoms and causes of death (11). However, the causes of sequelae in patients after sepsis remain unknown yet. Patients recovered from sepsis exhibit impaired immune function and a chronic inflammation state, similarly to elderly and immunosuppressed patients with inadequate response to infections (11)

Despite the information, the evolution of septic patients' survival after hospital discharge has drawn the attention of researchers worldwide. After curing sepsis and hospital discharge, septic patients' mortality is much higher than that of patients from any other disease.

We described the studies that investigated the percentage of septic patients that died after hospital discharge ranging from 90 days up to 5 years. We also reported the symptoms of septic patients after hospital discharge and the development of the post-sepsis syndrome (PSS) characterized by several clinical manifestations.

\section{METHODS}

We conducted a literature search on MEDLINE in PubMed, using relevant search terms and synonyms for sepsis, survivors, and long-term mortality, and excluded non-English language articles. We searched for retrieved studies to find other relevant data: clinical trials, large longitudinal, and observational studies.
We summarized recent insights into the outcome of septic patients after hospital discharge.

\section{THE RATES OF DEATH OF SEPTIC PATIENTS AFTER HOSPITAL DISCHARGE}

Table 1 shows the reports on this matter by several research groups. The authors described a substantial amount of patients who died as early as 90 days of the hospital discharge and during a follow up of 5 years. Next, we describe the literature data grouped by time of follow up: 1, 2, and 5 years.

Prescott, Langa (17), Yende, Kellum (22), and Courtright, Jordan (23) conducted cohort studies in septic patients. The authors had the main objective of assessing the mortality rate after one year of hospital discharge. The studies included 1,083, 483 , and 87,581 patients, respectively. The three studies showed similar results, with a death rate between 28 to $44 \%$. Yende, Kellum (22) demonstrated that in addition to the high mortality rate, survivors showed a persistent increase in the blood levels of inflammation and immunosuppression biomarkers associating these observations with worse long-term outcomes. Courtright, Jordan (23) also pointed out that $68.2 \%$ the patients who died were re-hospitalized in the last 30 days of life.

Jagodic and Podbregar (13), Karlsson, Ruokonen (14), Davis, He (19), and Prescott, Osterholzer (20) carried out observational studies intending to determine short and long-term survival, besides, to evaluate the quality of life of septic patients after the hospitalization period. The researchers studied 164, 470, and 1,092 patients, respectively. They concluded that septic patients have a high mortality rate after two years of hospital discharge compared to patients recovered from other diseases; the percentage of death ranged from $22 \%$ to $70 \%$. They also reported a marked reduction in the survivors' quality of life.

Quartin, Schein (12), Iwashyna, Ely (15), Cuthbertson, Elders (16) and Wang, Szychowski (18) performed cohort studies to determine long-term mortality in septic patients. The researchers investigated $1.505,1.194,439$, and 30.239 patients, respectively. The authors reported that the mortality rate varied between $44 \%$ and $100 \%$ of the total survivor's septic patients after five years of

TABLE 1 | Percentage of death of septic patients after hospital discharge.

\begin{tabular}{|c|c|c|c|c|c|c|c|}
\hline Authors & Number of patients & Country & Up to 90 days & Up to 1 year & Up to 2 years & Up to 5 years & Age (years) \\
\hline Quartin, Schein (12) & 1.505 & USA & $\mathrm{NI}$ & $66 \%$ & $\mathrm{NI}$ & $100 \%$ & $61,7 \pm 12.6$ \\
\hline Jagodic and Podbregar (13) & 164 & Slovenia & $\mathrm{NI}$ & $30 \%$ & $70 \%$ & $\mathrm{NI}$ & $64 \pm 13$ \\
\hline Karlsson, Ruokonen (14) & 470 & Finland & $\mathrm{NI}$ & $\mathrm{NI}$ & $44,9 \%$ & $\mathrm{NI}$ & $59,6 \pm 15,1$ \\
\hline Iwashyna, Ely (15) & 1.194 & USA & $41.3 \%$ & $\mathrm{NI}$ & $\mathrm{NI}$ & $\sim 82 \%$ & $76,9 \pm 8,7$ \\
\hline Cuthbertson, Elders (16) & 439 & Scotland & $\mathrm{NI}$ & $\mathrm{NI}$ & $\mathrm{NI}$ & $61 \%$ & 45 a 67 \\
\hline Prescott, Langa (17) & 1.083 & USA & $27.5 \%$ & $44.2 \%$ & $\mathrm{NI}$ & $\mathrm{NI}$ & $78,6 \pm 8,6$ \\
\hline Wang, Szychowski (18) & 30.239 & USA & $\mathrm{NI}$ & $23 \%$ & $\sim 29 \%$ & $\sim 44 \%$ & $\geq 45$ \\
\hline Davis, He (19) & 1.092 & Australia & $\mathrm{NI}$ & $12.5 \%$ & $22.4 \%$ & $\mathrm{NI}$ & $46,9 \pm 17,3$ \\
\hline Prescott, Osterholzer (20) & - & USA & $35.3 \%$ & $48.5 \%$ & $56.5 \%$ & $\mathrm{NI}$ & $\geq 65$ \\
\hline Shankar-Hari, Harrison (21) & 94.748 & England & $\mathrm{NI}$ & $15 \%$ & $8.3 \%$ & $21.1 \%$ & $61,3 \pm 17,0$ \\
\hline Yende, Kellum (22) & 483 & USA & $\sim 9 \%$ & $\sim 30 \%$ & $\mathrm{NI}$ & $\mathrm{NI}$ & $60,5 \pm 15,2$ \\
\hline Courtright, Jordan (23) & 87.581 & USA & $\mathrm{NI}$ & $\sim 28 \%$ & $\mathrm{NI}$ & $\mathrm{NI}$ & $\geq 75$ \\
\hline
\end{tabular}

NI, Not informed. 
hospital discharge. It is remarkable that in many cases there were no septic patients alive in the short period of five years after hospitalization. There is a possibility that the sepsis promotes an early aging state in the post-sepsis patients. This assumption is supported by the fact that aging markers such as telomeres shortage are increased in patients with sepsis (24).

\section{POST-SEPSIS SYNDROME (PSS)}

There is an association between preexisting comorbid conditions and some of the long-term outcomes following sepsis demonstrated by robust statistical methods. However, epidemiological causality and biological mechanisms are not fully established yet.

Charlson's Comorbidity Index allows determining the impact of comorbidities in the outcome of patients with severe infections or sepsis $(25,26)$. The weighted Charlson's Comorbidity Index assesses chronic diseases' presence to predict 10-year survival in patients with multiple comorbidities (27). There is also a high prevalence of comorbidities in post-septic patients - most studies listed in Table 1 report comorbidities (12, 13, 17, 18, 21, 23).

The post-sepsis-syndrome cognitive decline relationship is complex and bidirectional. Pre-illness cognitive decline is a risk factor for pneumonia and sepsis. On the other hand, sepsis is an independent risk factor for cognitive function decline (OR 95\% CI $3.3(1.5-7.3)(28,29)$. Other authors found that sepsis per se confers additional risk to late mortality predicted by status before sepsis itself (20). In fact, sepsis more often occurs in patients with preexisting chronicle conditions (14,30), for instance, frail and elderly (10).

In a previous study, we postulated that in elderly with sepsis, in addition to comorbidities, a combination of factors including intestinal barrier dysfunction and dysbiosis, DNA damage, mitochondrial dysfunction, telomere shortening, and epigenetic mechanisms have synergistic effects contributing to a worse outcome (31).

The diverse clinical manifestations in the post-septic patients have been named altogether as post-sepsis syndrome-PSS. The PSS syndrome includes various clinical manifestations such as changes in metabolism; for instance, a decrease in total body protein content, high retention volume of fluid, prolonged time for returning to normal hydration, and an increase in total energy expenditure (32-34). Several studies showed that post-sepsis syndrome also includes immune function impairments such as a persistent inflammatory state characterized by an increase in High mobility group box 1 (HMGB1) levels in plasma after sepsis (35-37). HMGB1 is a protein of the nucleus and binds to DNA acting as a co-factor for the transcription of certain genes. HMGB1 released into the extracellular fluid exhibits pro-inflammatory properties by working as a damage-associated molecular pattern molecule (DAMP). HMGB1 triggers innate immune responses through activation of various cell surface receptors; the receptor for advanced glycation end-products (RAGE) and toll-like receptors (TLRs); TLR2, TLR4, or TLR9 (38).

Monneret and Venet (37) described that neutrophils have impaired chemotaxis and oxidative burst activities. The authors also reported an increased number of circulating immature neutrophils. There is also evidence for impaired lymphocyte and natural killer cell functions. Sepsis survivors had a high level of re-hospitalizations, caused by pneumonia (18, 39-43) (including sepsis again). PSS also is characterized by cognitive sequelae, such as dementia (44-50) and changes in the cardiovascular system and cardiovascular diseases (51-55). These changes lead to a decrease in the quality of life of the pots-sepsis patients, with psychological alterations (e.g., anxiety, memory loss), and mental problems (incapability of doing easy calculations for instance) (56). Table 2 reports the symptoms post-sepsis patients more often exhibit. A summary of the PSS symptoms herein reported is in Figure 1.

Prescott, Langa (17) reported that of 2,617 septic patients survivors, $40 \%$ were admitted to the hospital again after 90 days. Readmissions were mainly due to a recurrence of sepsis (11.9\%), and also due to pneumonia and urinary tract or skin or soft tissue infections. The incidence of these infections was much higher in post-septic patients than patients who survived from other diseases.

In a study of 93,862 septic patients, one year after hospital discharge, survivors had a higher risk of developing cardiovascular events, such as ischemic and hemorrhagic stroke, myocardial infarction, and heart failure. The authors followed the patients for 5 years and reported risks for patients during the whole period of study. Five years of follow up reported $15.3 \%$ of patients with a mental decline, emotional, and behavioral conditions; $50.2 \%$ of those were re-hospitalized (54), 27.2\% needed respiratory treatments, and approximately $46 \%$ had declined on cognitive function (23).

Several studies use the Short Form Health Survey (SF-36) to evaluate the patients' quality of life $(44,59,60)$ through questions covering functional capacity, physical aspects, pain, general health, vitality, social issues, emotional elements, and mental health $(46,59)$. Sepsis or septic shock survival patients exhibit a poor and sometimes very poor quality of life (61). Hofhuis, Spronk (28) reported that even three months after hospital discharge, physical functioning recovery is incomplete (62). This condition persists until two years or more (59).

Septic patients do develop several limitations after leaving the hospital. It has been reported difficulties in performing straightforward daily activities, managing money, taking bathe, or using the toilet. These physical activity limitations are associated with myopathy, neuropathy, or cardio-respiratory problems, independently or together (15). Patients also have lost sensory, digestive, and kidney dysfunctions, skeletal muscle pain, and chest discomfort. Huang, Daniels (63) reported that of 1,731 patients, only $5.5 \%$ said they felt very well after sepsis. Most of them reported feeling worse or different from the conditions before the sepsis. The decline in the ability to read, spell, and libido occur concomitantly with anxiety, depression, and sleep disorders. 
TABLE 2 | Sequels in septic patients after hospital discharge.

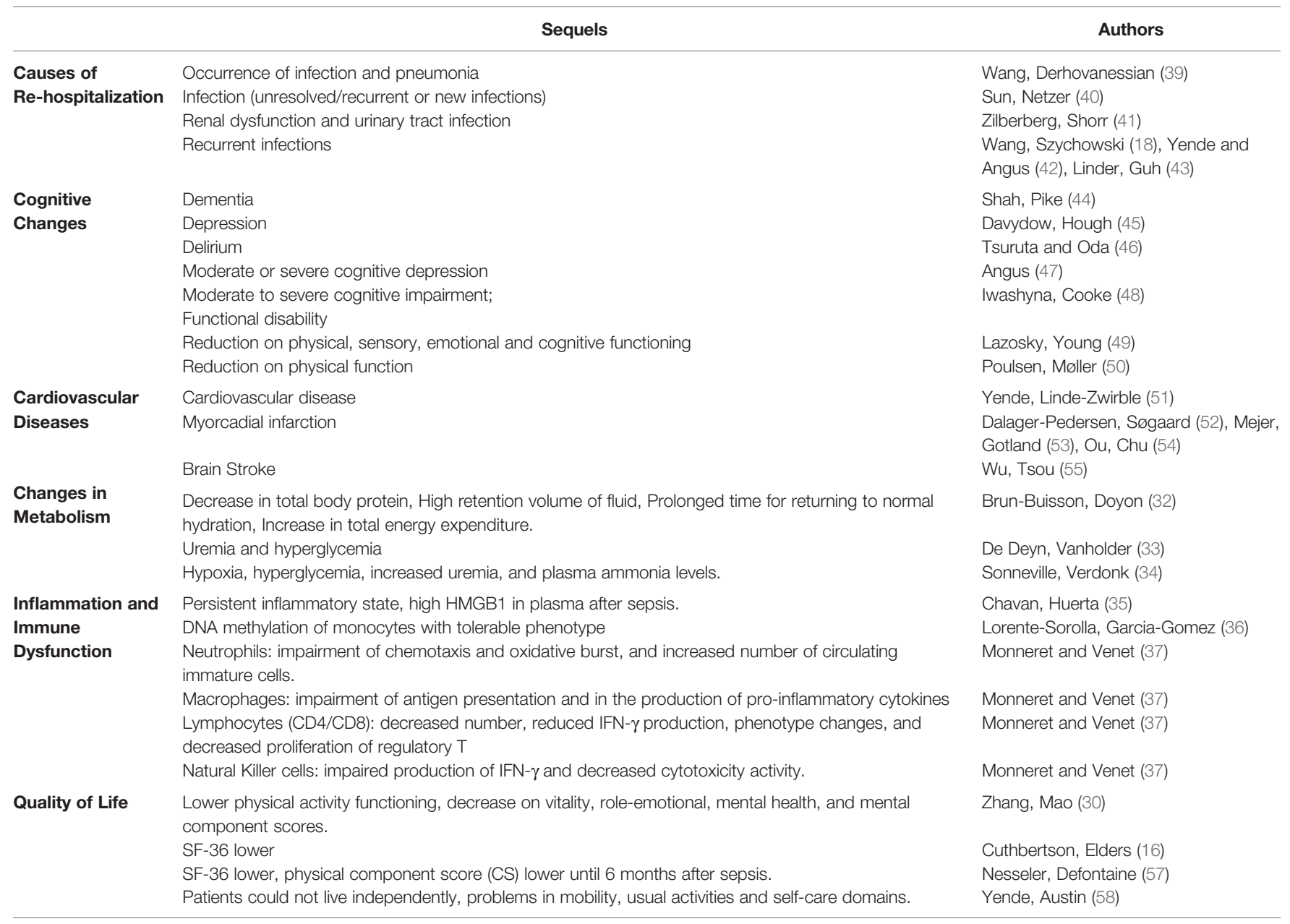

SF-36, Short-Form Health Survey; HMGB1:High Mobility Group Box 1 protein.

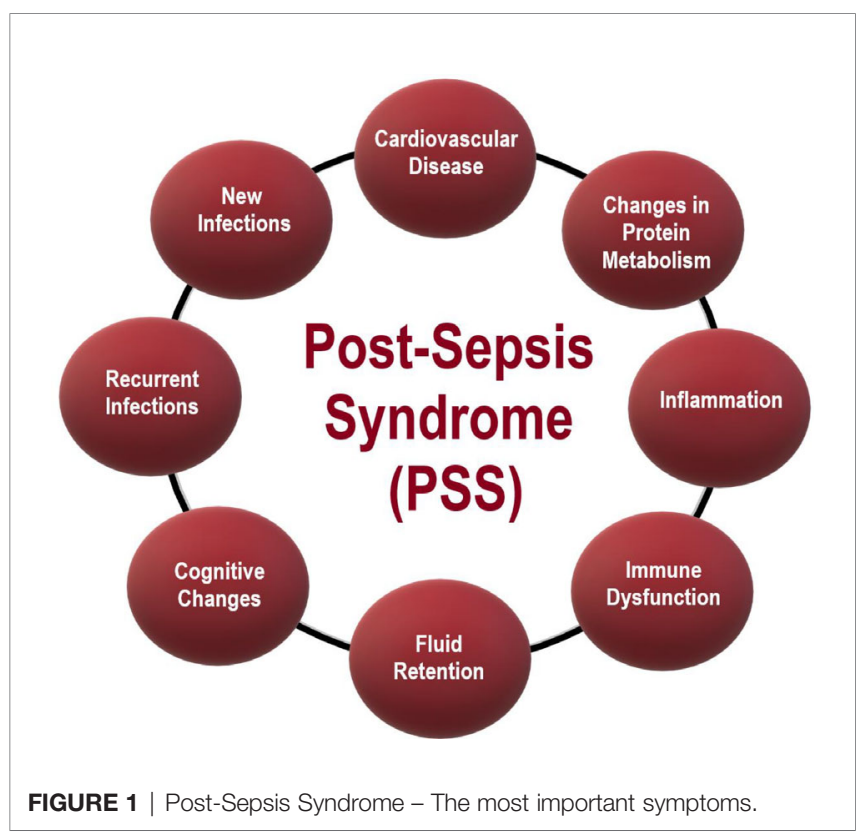

\section{DISCUSSION: INFERENCES AND INVESTIGATION DIRECTIONS}

The massive infection and the accompanying intense immune response with a cytokine outpouring during sepsis may promote irreversible cell metabolic reprogramming. The cell reprogramming is unlikely to occur in leukocytes or bone marrow only. These might happen in several tissues and cells that prompt to systemic organ dysfunctions. The cell metabolic reprogramming persists even after hospital discharge and might be associated with the PSS symptoms. In other words, a septic patient no more returns to the health state before the infection and hospitalization.

The molecular mechanisms associated with cell metabolic reprogramming in sepsis deserve investigation. Bacteria can transfer genetic material to host cell DNA (64) as the eukaryotic cells develop tools to protect themselves against the microorganism invasion (65). The latter may induce cell biology and metabolic reprogramming that remains even after the infection elimination. Particularly, miRNAs formed during sepsis can define a repertoire of gene expressions reprogramming different cells and 
tissues. This postulated molecular mechanism may explain the fact that PSS involves marked manifestations in widespread organs. Cell reprogramming might also involve epigenetic mechanisms such as DNA methylation and histones methylation or acetylation.

Leukocytes (macrophages, lymphocytes, and neutrophils) functions depend on the heterogeneity and the plasticity properties of these cells. Several research groups documented the plasticity of leukocytes in normal and disease conditions (66-68). All leukocytes have a recognized ability to sense the microenvironment and modify their cell biology and metabolism to accomplish the organism's requirements for that specific moment accordingly (69). Leukocytes can reprogram the intracellular metabolism quickly and efficiently to respond to inflammatory or infectious stimuli generating a different phenotype (70). The metabolism fate of leukocytes is closely associated with the phenotypes of these cells. The metabolic reprogramming is part of the leukocyte phenotyping plasticity.

Macrophage functions play a crucial role in the homeostasis, including involvement in inflammatory and immune responses. There are two macrophages types; (M1) pro- and (M2) anti-inflammatory macrophages (66). The polarization of macrophages involves marked changes in the intracellular metabolic pathways (71). M1 macrophages exhibit a high glycolytic activity that generates the required ATP in the cytosol, whereas M2 macrophages use the Krebs cycle and the mitochondrial oxidative phosphorylation (OXPHOS) for energy production $(72,73)$.

Sepsis causes marked changes in macrophage functions and increases M1 cell proportion, particularly in the acute phase. Macrophage metabolism reprogramming during sepsis (74-78) may remain after hospital discharge. On the other hand, sepsis may generate a specific macrophage phenotype (a suggested Msepsis monocyte with sepsis memory still to be investigated) that remains active up to three years after hospital discharge. In a previous study, we identified monocyte changes from septic patients even three years after ICU discharge by assessing mRNA expression of inflammatory mediators and monocyte polarization, indicating macrophage reprogramming (data not published).

Cell metabolism reprogramming is also involved in the functions and even generation of the different lymphocyte subsets. Several stimuli and conditions change lymphocyte metabolism (79), including microenvironment nutrient availability (80). The $\mathrm{T}$ helper lymphocyte (Th) maturation involves particular function acquisitions that result in the generation of Th1, Th2, and Th17 subsets. These effector T cells, particularly Th17, can generate other phenotypes under specific stimuli and disease conditions (81). It is remarkable to discover that glycolysis inhibition using 2-deoxyglucose, a nonmetabolizable compound that enters into the cells, converts the Th17 cells into Treg cells (82). Th17 lymphocytes can also generate non-classical Th1 cells with particular properties different from the classical ones. The mentioned Th17 plasticity may play an essential role in host protection and chronic inflammatory conditions (83). Metabolic reprogramming of the Th17 lymphocytes or even the generation of a particular lymphocyte subset in sepsis remains in question marks.
Another type of lymphocyte is Treg cells, responsible for maintaining immune self-tolerance and controlling autoimmune responses (84). Treg lymphocytes are essential regulators of the inflammatory response through secretion of cytokines that inhibit the action of effector T lymphocytes (CD4 + and CD8 +), culminating in the gradual decrease of the inflammatory response without harming the antigen response (84-86) reported that on the first day of septic condition, the percentage of Treg lymphocytes is higher in patients who survive than patients who die. The role of Treg lymphocytes in the PSS remains uninvestigated.

There are a large number of neutrophil phenotypes and functions in different tissues in health and diseases. Yang, Li (87) and Silvestre-Roig, Fridlender (88) reviewed the neutrophil phenotypes and tasks in various conditions such as inflammation and rheumatoid arthritis. Neutrophil kills microbes and exhibits high plasticity to accomplish its functions in situations of limited metabolite availability. We then speculate that a new subpopulation (to be described) of neutrophils (a suggested Nsepsis neutrophil with sepsis memory still to be investigated) develops and may remain even after hospital leaving during a sepsis or septic shock (24).

We presented herein directions for research to address the fact that septic patients remain sick after hospital discharge.

\section{STUDY LIMITATIONS}

This study has some limitations. We reviewed only English language articles and articles directly related to the subject of this study. Articles not directly related to the subject of the present study may be missing. We did not establish the relationship between comorbidities and the late outcome after sepsis due to the lack of information.

\section{DATA AVAILABILITY STATEMENT}

The original contributions presented in the study are included in the article/supplementary material. Further inquiries can be directed to the corresponding author.

\section{AUTHOR CONTRIBUTIONS}

Conceived and designed the Review: RG, TS-S and RC. Contributed to the preparation of the tables: RG, TS-S, RC, MM, and FS. Wrote the paper: RG, TS-S, RC, MM, and FS. Final approval of the version to be submitted: TS-S, RC, MM, and FS. All authors contributed to the article and approved the submitted version.

\section{FUNDING}

FAPESP, CNPq, CAPES, the Guggenheim Foundation, University Hospital of the University of Sao Paulo, University of São Paulo Medical School, Sirio Libanes Hospital of São Paulo, and Cruzeiro do Sul University financially support the research studies of our groups. 


\section{REFERENCES}

1. Bonet M, Pileggi VN, Rijken MJ, Coomarasamy A, Lissauer D, Souza JP, et al. Towards a consensus definition of maternal sepsis: results of a systematic review and expert consultation. Reprod Health (2017) 14(1):67. doi: 10.1186/ s12978-017-0321-6

2. Singer M, Deutschman CS, Seymour CW, Shankar-Hari M, Annane D, Bauer $\mathrm{M}$, et al. The third international consensus definitions for sepsis and septic shock (Sepsis-3). JAMA (2016) 315(8):801-10. doi: 10.1001/jama. 2016.0287

3. Morelli A, Passariello M. Hemodynamic coherence in sepsis. Best Pract Res Clin Anaesthesiol (2016) 30(4):453-63. doi: 10.1016/j.bpa.2016.10.009

4. Lin G-L, McGinley JP, Drysdale SB, Pollard AJ. Epidemiology and immune pathogenesis of viral sepsis. Front Immunol (2018) 9:2147. doi: 10.3389/ fimmu.2018.02147

5. Machado FR, Cavalcanti AB, Bozza FA, Ferreira EM, Carrara FSA, Sousa JL, et al. The epidemiology of sepsis in Brazilian intensive care units (the Sepsis PREvalence Assessment Database, SPREAD): an observational study. Lancet Infect Dis (2017) 17(11):1180-9. doi: 10.1016/S1473-3099(17) 30322-5

6. Azevedo LCP, Cavalcanti AB, Lisboa T, Pizzol FD, Machado FR. A sepse é um grave problema de saúde na América Latina: uma chamada à ação! Rev Bras Terapia Intensiva (2018) 30(4):402-4. doi: 10.5935/0103-507X. 20180061

7. Rudd KE, Johnson SC, Agesa KM, Shackelford KA, Tsoi D, Kievlan DR, et al. Global, regional, and national sepsis incidence and mortality, 1990-2017: analysis for the Global Burden of Disease Study. Lancet (2020) 395 (10219):200-11. doi: 10.1016/S0140-6736(19)32989-7

8. Paoli CJ, Reynolds MA, Sinha M, Gitlin M, Crouser E. Epidemiology and costs of sepsis in the United States-an analysis based on timing of diagnosis and severity level. Crit Care Med (2018) 46(12):1889. doi: 10.1097/ CCM.0000000000003342

9. Burchardi H, Schneider H. Economic aspects of severe sepsis. Pharmacoeconomics (2004) 22(12):793-813. doi: 10.2165/00019053-200422120-00003

10. Conde KAP, Silva E, Silva CO, Ferreira E, Freitas FGR, Castro I, et al. Differences in sepsis treatment and outcomes between public and private hospitals in Brazil: a multicenter observational study. PloS One (2013) 8(6): e64790. doi: 10.1371/journal.pone.0064790

11. Grander W, Dünser MW. Prolonged inflammation following critical illness may impair long-term survival: a hypothesis with potential therapeutic implications. Med Hypotheses (2010) 75(1):32-4. doi: 10.1016/ j.mehy.2010.01.020

12. Quartin AA, Schein RM, Kett DH, Peduzzi PN. Magnitude and duration of the effect of sepsis on survival. JAMA (1997) 277(13):1058-63. doi: 10.1001/ jama.277.13.1058

13. Jagodic HK, Podbregar M. Long-term outcome and quality of life of patients treated in surgical intensive care: a comparison between sepsis and trauma. Crit Care (2006) 10(1):1-. doi: 10.1186/cc5047

14. Karlsson S, Ruokonen E, Varpula T, Ala-Kokko TI, Pettilä V, Group FS. Longterm outcome and quality-adjusted life years after severe sepsis. Crit Care Med (2009) 37(4):1268-74. doi: 10.1097/CCM.0b013e31819c13ac

15. Iwashyna TJ, Ely EW, Smith DM, Langa KM. Long-term cognitive impairment and functional disability among survivors of severe sepsis. Jama (2010) 304(16):1787-94. doi: 10.1001/jama.2010.1553

16. Cuthbertson BH, Elders A, Hall S, Taylor J, MacLennan G, Mackirdy F, et al. Mortality and quality of life in the five years after severe sepsis. Crit Care (2013) 17(2):R70. doi: 10.1186/cc12616

17. Prescott HC, Langa KM, Liu V, Escobar GJ, Iwashyna TJ. Increased 1-year healthcare use in survivors of severe sepsis. Am J Respir Crit Care Med (2014) 190(1):62-9. doi: 10.1164/rccm.201403-0471OC

18. Wang HE, Szychowski JM, Griffin R, Safford MM, Shapiro NI, Howard G. Long-term mortality after community-acquired sepsis: a longitudinal population-based cohort study. BMJ Open (2014) 4(1):1-8. doi: 10.1136/ bmjopen-2013-004283

19. Davis JS, He V, Anstey NM, Condon JR. Long term outcomes following hospital admission for sepsis using relative survival analysis: a prospective cohort study of 1,092 patients with 5 year follow up. PloS One (2014) 9(12): e112224. doi: 10.1371/journal.pone.0112224
20. Prescott HC, Osterholzer JJ, Langa KM, Angus DC, Iwashyna TJ. Late mortality after sepsis: propensity matched cohort study. BMJ (2016) 353:1-8. doi: 10.1136/bmj.i2375

21. Shankar-Hari M, Harrison DA, Ferrando-Vivas P, Rubenfeld GD, Rowan K. Risk factors at index hospitalization associated with longer-term mortality in adult sepsis survivors. JAMA Netw Open (2019) 2(5):e194900-e. doi: 10.1001/ jamanetworkopen.2019.4900

22. Yende S, Kellum JA, Talisa VB, Palmer OMP, Chang C-CH, Filbin MR, et al. Long-term host immune response trajectories among hospitalized patients with sepsis. JAMA Netw Open (2019) 2(8):e198686-e. doi: 10.1001/ jamanetworkopen.2019.8686

23. Courtright KR, Jordan L, Murtaugh CM, Barrón Y, Deb P, Moore S, et al. Risk Factors for Long-term Mortality and Patterns of End-of-Life Care Among Medicare Sepsis Survivors Discharged to Home Health Care. JAMA Netw Open (2020) 3(2):e200038-e. doi: 10.1001/jamanetworkopen.2020.0038

24. Oliveira NM, Rios EC, de Lima TM, Victorino VJ, Barbeiro H, da Silva FP, et al. Sepsis induces telomere shortening: a potential mechanism responsible for delayed pathophysiological events in sepsis survivors? Mol Med (2016) 22 (1):886-91. doi: 10.2119/molmed.2016.00225

25. Payá-Llorente C, Martínez-López E, Sebastián-Tomás JC, SantarrufinaMartínez S, de'Angelis N, Martínez-Pérez A. The impact of age and comorbidity on the postoperative outcomes after emergency surgical management of complicated intra-abdominal infections. Sci Rep (2020) 10 (1):1-8. doi: 10.1038/s41598-020-58453-1

26. Cui Y, Wang T, Bao J, Tian Z, Lin Z, Chen D. Comparison of Charlson's weighted index of comorbidities with the chronic health score for the prediction of mortality in septic patients. Chin Med J (2014) 127(14):2623-7.

27. Charlson ME, Pompei P, Ales KL, MacKenzie CR. A new method of classifying prognostic comorbidity in longitudinal studies: development and validation. J Clin Epidemiol (1987) 40(5):373-83. doi: 10.1016/0021-9681(87) 90171-8

28. Hofhuis JG, Spronk PE, van Stel HF, Schrijvers AJ, Rommes JH, Bakker J. The impact of severe sepsis on health-related quality of life: a long-term follow-up study. Anesthesia Analgesia (2008) 107(6):1957-64. doi: 10.1213/ ane.0b013e318187bbd8

29. Shankar-Hari M, Rubenfeld GD. Understanding long-term outcomes following sepsis: implications and challenges. Curr Infect Dis Rep (2016) 18 (11):37. doi: 10.1007/s11908-016-0544-7

30. Zhang K, Mao X, Fang Q, Jin Y, Cheng B, Xie G, et al. Impaired long-term quality of life in survivors of severe sepsis. Der Anaesthesist (2013) 62 (12):995-1002. doi: 10.1007/s00101-013-2257-8

31. Pinheiro da Silva F, Machado MCC. septic shock and the aging process: a Molecular Comparison. Front Immunol (2017) 8:1389. doi: 10.3389/ fimmu.2017.01389

32. Brun-Buisson C, Doyon F, Carlet J, Dellamonica P, Gouin F, Lepoutre A, et al. Incidence, risk factors, and outcome of severe sepsis and septic shock in adults: a multicenter prospective study in intensive care units. JAMA (1995) 274(12):968-74. doi: 10.1001/jama.274.12.968

33. De Deyn PP, Vanholder R, Eloot S, Glorieux G. Progress in uremic toxin research: guanidino compounds as uremic (neuro) toxins. In: Seminars in dialysis. Wiley Online Library, Oxford, UK: Blackwell Publishing Ltd. (2009) 22(4):340-45. doi: 10.1111/j.1525-139x.2009.00577.x

34. Sonneville R, Verdonk F, Rauturier C, Klein IF, Wolff M, Annane D, et al. Understanding brain dysfunction in sepsis. Ann Intensive Care (2013) 3(1):15. doi: 10.1186/2110-5820-3-15

35. Chavan SS, Huerta PT, Robbiati S, Valdes-Ferrer S, Ochani M, Dancho M, et al. HMGB1 mediates cognitive impairment in sepsis survivors. Mol Med (2012) 18(6):930-7. doi: 10.2119/molmed.2012.00195

36. Lorente-Sorolla C, Garcia-Gomez A, Català-Moll F, Toledano V, AvendañoOrtiz J, Maroun-Eid C, et al. Inflammatory cytokines and organ dysfunction associate with the aberrant DNA methylome of monocytes in sepsis. Genome Med (2019) 11(1):1-18. doi: 10.1186/s13073-019-0674-2

37. Monneret G, Venet F. Sepsis-induced immune alterations monitoring by flow cytometry as a promising tool for individualized therapy. Cytometry Part B: Clin Cytometry (2016) 90(4):376-86. doi: 10.1002/cyto.b.21270

38. Chen Q, Guan X, Zuo X, Wang J, Yin W. The role of high mobility group box 1 (HMGB1) in the pathogenesis of kidney diseases. Acta Pharm Sin B (2016) 6 (3):183-8. doi: 10.1016/j.apsb.2016.02.004 
39. Wang T, Derhovanessian A, De Cruz S, Belperio JA, Deng JC, Hoo GS. Subsequent infections in survivors of sepsis: epidemiology and outcomes. J Intensive Care Med (2014) 29(2):87-95. doi: 10.1177/0885066612467162

40. Sun A, Netzer G, Small DS, Hanish A, Fuchs BD, Gaieski DF, et al. Association between index hospitalization and hospital readmission in sepsis survivors. Crit Care Med (2016) 44(3):478-87. doi: 10.1097/CCM.0000000000001464

41. Zilberberg MD, Shorr AF, Micek ST, Kollef MH. Risk factors for 30-day readmission among patients with culture-positive severe sepsis and septic shock: A retrospective cohort study. J Hosp Med (2015) 10(10):678-85. doi: $10.1002 / \mathrm{jhm} .2420$

42. Yende S, Angus DC. Long-term outcomes from sepsis. Curr Infect Dis Rep (2007) 9(5):382-6. doi: 10.1007/s11908-007-0059-3

43. Linder A, Guh D, Boyd JH, Walley KR, Anis AH, Russell JA. Long-term (10-year) mortality of younger previously healthy patients with severe sepsis/ septic shock is worse than that of patients with nonseptic critical illness and of the general population. Crit Care Med (2014) 42(10):2211-8. doi: 10.1097/ CCM.0000000000000503

44. Shah FA, Pike F, Alvarez K, Angus D, Newman AB, Lopez O, et al. Bidirectional relationship between cognitive function and pneumonia. Am J Respir Crit Care Med (2013) 188(5):586-92. doi: 10.1164/rccm.2012122154OC

45. Davydow DS, Hough CL, Langa KM, Iwashyna TJ. Symptoms of depression in survivors of severe sepsis: a prospective cohort study of older Americans. Am J Geriatr Psychiatry (2013) 21(9):887-97. doi: 10.1016/j.jagp.2013.01.017

46. Tsuruta R, Oda Y. A clinical perspective of sepsis-associated delirium. J Intensive Care (2016) 4(1):18. doi: 10.1186/s40560-016-0145-4

47. Angus DC. The lingering consequences of sepsis: a hidden public health disaster? JAMA (2010) 304(16):1833-4. doi: 10.1001/jama.2010.1546

48. Iwashyna TJ, Cooke CR, Wunsch H, Kahn JM. Population burden of longterm survivorship after severe sepsis in older Americans. J Am Geriatr Soc (2012) 60(6):1070-7. doi: 10.1111/j.1532-5415.2012.03989.x

49. Lazosky A, Young GB, Zirul S, Phillips R. Quality of life after septic illness. J Crit Care (2010) 25(3):406-12. doi: 10.1016/j.jcrc.2009.10.001

50. Poulsen J, Møller K, Kehlet H, Perner A. Long-term physical outcome in patients with septic shock. Acta Anaesthesiologica Scand (2009) 53(6):724-30. doi: 10.1111/j.1399-6576.2009.01921.x

51. Yende S, Linde-Zwirble W, Mayr F, Weissfeld LA, Reis S, Angus DC. Risk of cardiovascular events in survivors of severe sepsis. Am J Respir Crit Care Med (2014) 189(9):1065-74. doi: 10.1164/rccm.201307-1321OC

52. Dalager-Pedersen M, Søgaard M, Schønheyder HC, Nielsen H, Thomsen RW. Risk for myocardial infarction and stroke after community-acquired bacteremia: a 20-year population-based cohort study. Circulation (2014) 129(13):1387-96. doi: 10.1161/CIRCULATIONAHA.113.006699

53. Mejer N, Gotland N, Uhre M, Westh H, Schønheyder H, Petersen A, et al. Increased risk of arterial thromboembolic events after Staphylococcus aureus bacteremia: a matched cohort study. J Infect (2015) 71(2):167-78. doi: 10.1016/j.jinf.2015.03.010

54. Ou S-M, Chu H, Chao P-W, Lee Y-J, Kuo S-C, Chen T-J, et al. Long-term mortality and major adverse cardiovascular events in sepsis survivors. A nationwide population-based study. Am J Respir Crit Care Med (2016) 194 (2):209-17. doi: 10.1164/rccm.201510-2023OC

55. Wu M-H, Tsou P-Y, Wang Y-H, M-tG L, Chao CCT, Lee W-C, et al. Impact of post-sepsis cardiovascular complications on mortality in sepsis survivors: a population-based study. Crit Care (2019) 23(1):293. doi: 10.1186/s13054-0192579-2

56. Mostel Z, Perl A, Marck M, Mehdi SF, Lowell B, Bathija S, et al. Post-sepsis syndrome-an evolving entity that afflicts survivors of sepsis. Mol Med (2020) 26(1):6. doi: 10.1186/s10020-019-0132-z

57. Nesseler N, Defontaine A, Launey Y, Morcet J, Mallédant Y, Seguin P. Longterm mortality and quality of life after septic shock: a follow-up observational study. Intensive Care Med (2013) 39(5):881-8. doi: 10.1007/s00134-013-2815-1

58. Yende S, Austin S, Rhodes A, Finfer S, Opal S, Thompson T, et al. Long-term quality of life among survivors of severe sepsis: analyses of two international trials. Crit Care Med (2016) 44(8):1461. doi: 10.1097/CCM.0000000 000001658

59. Battle CE, Davies G, Evans PA. Long term health-related quality of life in survivors of sepsis in South West Wales: an epidemiological study. PloS One (2014) 9(12):e116304. doi: 10.1371/journal.pone.0116304
60. Heyland DK, Hopman W, Coo H, Tranmer J, McColl MA. Long-term healthrelated quality of life in survivors of sepsis. Short Form 36: a valid and reliable measure of health-related quality of life. Crit Care Med (2000) 28(11):3599605. doi: 10.1097/00003246-200011000-00006

61. Pandharipande PP, Girard TD, Jackson JC, Morandi A, Thompson JL, Pun BT, et al. Long-term cognitive impairment after critical illness. New Engl J Med (2013) 369(14):1306-16. doi: 10.1056/NEJMoa1301372

62. Borges RC, Carvalho CR, Colombo AS, da Silva Borges MP, Soriano FG. Physical activity, muscle strength, and exercise capacity 3 months after severe sepsis and septic shock. Intensive Care Med (2015) 41(8):1433-44. doi: 10.1007/s00134-015-3914-y

63. Huang CY, Daniels R, Lembo A, Hartog C, O’Brien J, Heymann T, et al. Life after sepsis: an international survey of survivors to understand the post-sepsis syndrome. Int J Qual Health Care (2019) 31(3):191-8. doi: 10.1093/intqha/ mzy137

64. Lacroix B, Citovsky V. Transfer of DNA from bacteria to eukaryotes. MBio (2016) 7(4):1-9. doi: 10.1128/mBio.00863-16

65. Keller MD, Ching KL, Liang F-X, Dhabaria A, Tam K, Ueberheide BM, et al. Decoy exosomes provide protection against bacterial toxins. Nature (2020) 579(7798):260-4. doi: 10.1038/s41586-020-2066-6

66. Viola A, Munari F, Sánchez-Rodríguez R, Scolaro T, Castegna A. The metabolic signature of macrophage responses. Front Immunol (2019) 10:116. doi: $10.3389 /$ fimmu.2019.01462

67. Wan Z, Zhou Z, Liu Y, Lai Y, Luo Y, Peng X, et al. Regulatory T cells and T helper 17 cells in viral infection. Scand J Immunol (2020) 91(5):e12873. doi: $10.1111 /$ sji.12873

68. Kumar S, Dikshit M. Metabolic insight of neutrophils in health and disease. Front Immunol (2019) 10:2099. doi: 10.3389/fimmu.2019.02099

69. O’Neill LA, Kishton RJ, Rathmell J. A guide to immunometabolism for immunologists. Nat Rev Immunol (2016) 16(9):553. doi: 10.1038/nri.2016.70

70. Pålsson-McDermott EM, O'Neill LA. Targeting immunometabolism as an anti-inflammatory strategy. Cell Res (2020) 30(4):300-14. doi: 10.1038/ s41422-020-0291-z

71. Williams NC, O'Neill LA. A role for the krebs cycle intermediate citrate in metabolic reprogramming in innate immunity and inflammation. Front Immunol (2018) 9:141. doi: 10.3389/fimmu.2018.00141

72. Galván-Peña S, O’Neill LA. Metabolic reprograming in macrophage polarization. Front Immunol (2014) 5:420. doi: 10.3389/fimmu.2014.00420

73. Newsholme P, Curi R, Gordon S, Newsholme EA. Metabolism of glucose, glutamine, long-chain fatty acids and ketone bodies by murine macrophages. Biochem J (1986) 239(1):121-5. doi: 10.1042/bj2390121

74. Shalova IN, Lim JY, Chittezhath M, Zinkernagel AS, Beasley F, HernándezJiménez E, et al. Human monocytes undergo functional re-programming during sepsis mediated by hypoxia-inducible factor- $1 \alpha$. Immunity (2015) 42 (3):484-98. doi: 10.1016/j.immuni.2015.02.001

75. Dominguez-Andres J, Netea MG. Long-term reprogramming of the innate immune system. J Leukocyte Biol (2019) 105(2):329-38. doi: 10.1002/ JLB.MR0318-104R

76. Riedemann NC, Guo R-F, Ward PA. Novel strategies for the treatment of sepsis. Nat Med (2003) 9(5):517-24. doi: 10.1038/nm0503-517

77. Hotchkiss RS, Monneret G, Payen D. Immunosuppression in sepsis: a novel understanding of the disorder and a new therapeutic approach. Lancet Infect Dis (2013) 13(3):260-8. doi: 10.1016/S1473-3099(13)70001-X

78. Santos SS, Carmo AM, Brunialti MK, Machado FR, Azevedo LC, Assunção M, et al. Modulation of monocytes in septic patients: preserved phagocytic activity, increased ROS and NO generation, and decreased production of inflammatory cytokines. Intensive Care Med Exp (2016) 4(1):5. doi: 10.1186/ s40635-016-0078-1

79. Martins de Lima T, Gorjão R, Hatanaka E, Cury-Boaventura MF, Portioli Silva EP, Procopio J, et al. Mechanisms by which fatty acids regulate leucocyte function. Clin Sci (2007) 113(2):65-77. doi: 10.1042/ CS20070006

80. Cassim S, Pouyssegur J. Tumor microenvironment: a metabolic player that shapes the immune response. Int J Mol Sci (2020) 21(1):157. doi: 10.3390/ ijms 21010157

81. Harbour SN, Maynard CL, Zindl CL, Schoeb TR, Weaver CT. Th17 cells give rise to Th1 cells that are required for the pathogenesis of colitis. Proc Natl Acad Sci (2015) 112(22):7061-6. doi: 10.1073/pnas.1415675112 
82. Shi LZ, Wang R, Huang G, Vogel P, Neale G, Green DR, et al. HIF1 $\alpha-$ dependent glycolytic pathway orchestrates a metabolic checkpoint for the differentiation of TH17 and Treg cells. J Exp Med (2011) 208(7):1367-76. doi: 10.1084/jem.20110278

83. Mazzoni A, Maggi L, Liotta F, Cosmi L, Annunziato F. Biological and clinical significance of T helper 17 cell plasticity. Immunology (2019) 158(4):287-95. doi: $10.1111 /$ imm.13124

84. Wisnoski N, Chung C-S, Chen Y, Huang X, Ayala A. The contribution of CD4+ CD25+ T-regulatory-cells to immune suppression in sepsis. Shock (Augusta Ga) (2007) 27(3):251. doi: 10.1097/01.shk.0000239780. 33398.e4

85. Kumar A, Kumar A, Michael P, Brabant D, Parissenti AM, Ramana CV, et al. Human serum from patients with septic shock activates transcription factors STAT1, IRF1, and NF- $\mathrm{\kappa B}$ and induces apoptosis in human cardiac myocytes. J Biol Chem (2005) 280(52):42619-26. doi: 10.1074/jbc.M508416200

86. Wu L, Gabriel C, Parekh V, Van Kaer L. Invariant natural killer T cells: innate-like T cells with potent immunomodulatory activities. Tissue Antigens (2009) 73(6):535-45. doi: 10.1111/j.1399-0039.2009.01256.x
87. Yang P, Li Y, Xie Y, Liu Y. Different faces for different places: heterogeneity of neutrophil phenotype and function. I Immunol Res (2019) 2019:1-8. doi: $10.1155 / 2019 / 8016254$

88. Silvestre-Roig C, Fridlender ZG, Glogauer M, Scapini P. Neutrophil diversity in health and disease. Trends Immunol (2019) 40(7):565-83. doi: 10.1016/ j.it.2019.04.012

Conflict of Interest: The authors declare that the research was conducted in the absence of any commercial or financial relationships that could be construed as a potential conflict of interest.

Copyright (c) 2021 Gritte, Souza-Siqueira, Curi, Machado and Soriano. This is an open-access article distributed under the terms of the Creative Commons Attribution License (CC BY). The use, distribution or reproduction in other forums is permitted, provided the original author(s) and the copyright owner(s) are credited and that the original publication in this journal is cited, in accordance with accepted academic practice. No use, distribution or reproduction is permitted which does not comply with these terms. 